\title{
Modeling Strategic-Knowledge-Resource Management Based on Individual Competencies in SMEs
}

\author{
Justyna Patalas-Maliszewska' ${ }^{1}$, Martin Hochmeister ${ }^{2}$
}

\begin{abstract}
A number of publications have dealt with the correlation between knowledge-management capability and competitiveness. In the article describing human resources as strategic-knowledge resources, which is motivated by: the concept of effective management of resources in an organization (Sirmon and Hitt, 2003), an enterprise's unique potential in the form of knowledge and experience (Barney, 1995), and the concept of competence management (Hamel and Prahalad, 1994). This study describes competence and resource management, sharing in the collaborative development and implementation of strategic-knowledge-resource management in SMEs. In this context, strategic-knowledge resources are defined in such a way as to be incorporated into a model of strategic-knowledge-resource management.
\end{abstract}

KEY WORDS: $\quad$ strategic-knowledge resources, competence management, resource management

\footnotetext{
1 University of Zielona Gora, Poland; Vienna University of Technology, Austria.

${ }^{2}$ Vienna University of Technology, Austria.
}

\section{Introduction}

Nowadays, enterprises perceive knowledge as a strategic resource which contributes to the competitive dominance of an enterprise. Small and medium-sized enterprises (SMEs) play a critical role in creating work places and, in a more general sense, they also constitute factors in social stability and economic development. However, given the limited guarantees they can offer, SMEs often encounter difficulties in obtaining capital or credit as well as the fact that they typically have limited access to information concerning new technologies and potential markets.

Corespondence concerning to this article should be addressed to: j.patalas@iizp.uz.zgora.pl
A number of publications have dealt with the correlation between knowledge-management capability and competitiveness. Liu et al. (2001) suggested that taking advantage of knowledge management could stimulate employee potential and accelerate the integration of employee knowledge. Introducing knowledge management has become inevitable for enterprises, which need to survive in a competitive environment. The respect and adoption of the intelligence of each employee is the key to continuous company management (Davenport and Prusak, 1998). Nonaka and Takeuchi (1995) defined tacit knowledge as a kind of personal characteristic that is too abstract to transfer, one which cannot be expressed using words.

Many studies have focused on knowledge-management strategies from an organisational perspective (Bar- 
thelme et. al., 1998; Basu, 1998; Carayannis, 1998; Drew, 1999; Purser and Pasmore, 1992; Studer et. al., 1998; Staniewski, 2005, 2008). Sirmon and Hitt (2003) suggest the primary processes for the effective management of resources in an organisation. The first process is the structuring of the resource portfolio. This requires firms to engage in the acquisition and development of resources and, when necessary, remove less valuable resources. The second process entails bundling resources together in order to build unique and valuable capabilities.

Thus, describing human resources as strategicknowledge resources is motivated by:

- the concept of effective management of resources in an organisation (Sirmon and Hitt, 2003),

- an enterprise's unique potential in the form of knowledge and experience (Barney, 1995),

- the concept of competence management (Hamel and Prahalad, 1994).

A strategic-knowledge resource in a company represents the knowledge, skills and capabilities of the individuals, who make up the workforce of that company. Such resources are usually reflected by a person's education, experience and specific identifiable skills (Hitt et al., 2001). Yet, how can resources be managed to create added value for an enterprise?

Makadok (2001) presented several stages in the management of a firm's resources. Sirmon and Hitt (2003) expanded Makadok's work to develop a model of how resources could be managed to create value. We can use their model to examine five stages in the management of a firm's strategic-knowledge resources. The stages involve: identification, analysis, evaluation, configuration and forecasting (see point 3 ).

Therefore, the following research problem has been formulated: There are SMEs with a defined functional area and a set of business processes. There is a set of values of the strategic-knowledge resources of a given company. What is needed is a model of strategic knowledge-resource management which creates the added value for enterprise.

Besides determining a model of strategic-knowledge-resource management in SMEs, the following steps are required: (1) a description of competence management and a description of resource management, (2) a description of a set of values of the strategic-knowledge resources of a company according to a reference model SME.
This study describes competence and resource management, sharing in the collaborative development and implementation of strategic-knowledge-resource management in SMEs. In this context, strategicknowledge resources are defined in such a way as to be incorporated into a model of strategic-knowledgeresource management.

\section{Strategic-knowledge resources}

Resources are clearly important to the performance of a firm. Yet, according to the resource management, the issue of whether or not an organisation gains a competitive advantage and any associated returns depends on the strategic planning used to leverage those resources (Chrisman et al., 2003; McGrath and MacMillan, 2000).

Therefore, a firm's level of strategic planning may impact the degree, to which altruism and human and technological resources affect performance. Specifically, strategic planning may improve the positive effects of technological and human resources on the performance of a firm because the long-term nature of SMEs (especially small-family firms) allows them to strategically plan the dedication of resources required for innovation and risk taking (Zahra et al., 2004).

To define a company's strategic-knowledge resources, it is essential to understand the characteristics of competence and resource management.

\subsection{Competence management}

The significance of competence management in knowledge-intensive businesses is well-established. As a subdivision of knowledge management, competence management deals with the knowledge of individuals, i.e. their competencies. The capabilities of individuals to accomplish a task are often referred to as qualifications, skills, competencies or other similar terms. However, in literature, there is an explicit difference between these concepts. The concept of a competence is represented by a combination of knowledge, behaviour and skills, that gives an individual the potential to perform a task effectively (Draganidis and Mentzas, 2006).

The aim of competence management is to plan, implement and evaluate initiatives that ensure that the proper competencies are available to a company, which requires them to achieve its business objectives (Nordhaug, 1993). In order to support this task, Berio and 
Harzallah (2005) define four processes for competence management:

1. competence identification to define the required competence;

2. competence assessment to determine if a competence has been acquired;

3. competence acquisition to plan how required competencies can be acquired;

4. competence usage to systematically utilise knowledge about competencies for the benefit of an organisation.

To preserve a company's competitive edge, it is an inevitable necessity that a competence-management system be developed. In general terms, competence management operates on two levels: the macro- and the micro-. The former is concerned with core competencies and is controlled by business management. Thereby, a core competence is understood as the total collective knowledge and capabilities that reside in an organisation (Hamel and Prahalad, 1994). On the micro-level, led by humanresource management, the focus lies on the competencies of individual employees. The competencies a company requires to meet its strategic goals are transformed from the macro- to the micro-level. Inversely, existing competencies on the micro-level are exchanged via business management to support strategy design.

\subsection{Resource management}

Resource management is critical to the management of a firm and the gaining of a competitive advantage (Chrisman et al., 2003). In particular, a human resource can act as an important strategic resource that can lead to a distinct advantage. According to a resource-based view, firms can develop unique characteristics that allow them to gain a sustainable competitive advantage, thus positively affecting their performance. A further element of the resource-based view is that resources alone do not confer a competitive advantage. Firms must also allocate resources for strategic activities, deploy them effectively to obtain a sustainable competitive advantage and accomplish strategic objectives. Therefore, in order to succeed, firms must develop resources that cannot be easily imitated and are firm-specific, embedded in the organisation and non-transferable (Makadok, 2001).

Enterprises functioning in a market economy have to implement changes in the systems of organisation and management that they use. In economic practice, mak- ing a decision in an enterprise is typically conditioned by the actions of competitors and changing environmental factors, e.g. technical progress and the results of research. The added value for SMEs can be defined as knowledge, the skills and abilities of employees, social relations, know-how, and effective investment in intellectual capital. Enterprises, which invest in human capital, usually achieve a competitive advantage because of their workers' readiness to learn and qualify, and also thanks to effective information and communication transfer (Edvinsson and Malone, 2001).

While resources are important to the performance of a firm, according to a resource-based view, whether or not an organisation gains a competitive advantage and any associated returns, depends on the strategic planning used to leverage those resources (Chrisman et al., 2003; McGrath and MacMillan, 2000).

The need to describe a strategic-knowledge resource is motivated by the concept of resource management (Sirmon and Hitt, 2003) as well as competence management (Berio and Harzallah, 2005) - see Fig. 1.

\section{Modeling strategic-knowledge-re- source management}

To facilitate the use of the model of strategic-knowledge-resource management in SMEs, we build a reference model (Patalas-Maliszewska and Werthner, 2010). For SMEs, which belong to the reference model, we can define the value of strategic-knowledge resources (the so-called personnel usefulness function).

The business processes to be modeled are activities, which focus on sales in SMEs. We can distinguish the description of workplaces and the value of strategicknowledge resources: the so-called personnel usefulness function (see Fig. 1). This function is defined for each employee who realises a determined set of business processes (Patalas-Maliszewska and Werthner, 2010).

The personnel usefulness function (see Fig. 1) describes the strategic knowledge resource in SMEs. We distinguish the strategic knowledge resource in the sale are in SME based on the identification of business processes and their characteristics in SMEs:

- $\mathrm{m} 1$ - Sales Director

- m2 - Sales Specialist

- m3 -Marketing Specialist

- m4 - Regional Assistant

- m5 - Product Manager 
Figure 1. Strategic Knowledge Resource in SMEs

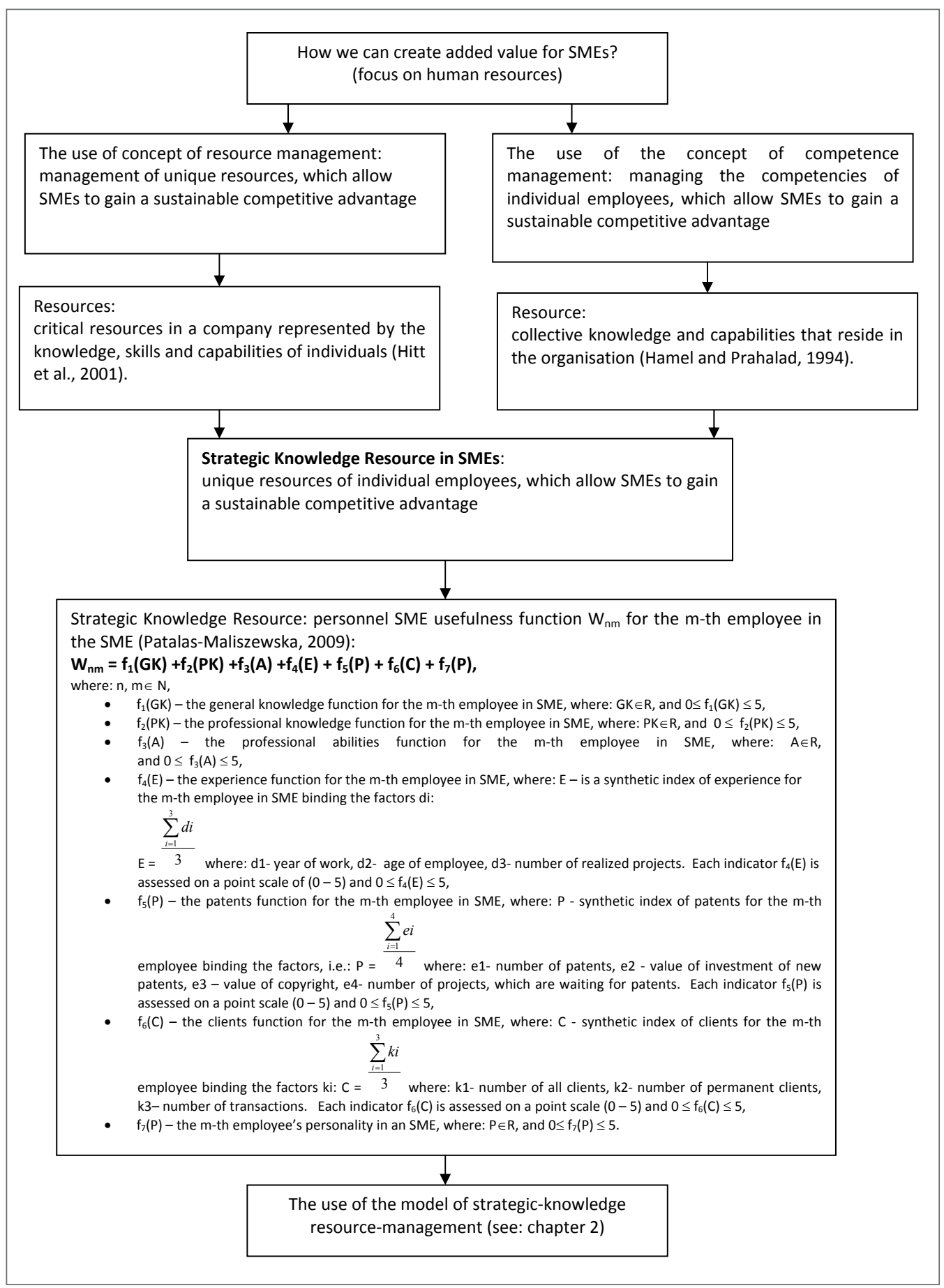


It was possible to receive indispensable data on account of the value personnel usefulness function from companies belonging to the reference model of SME by interview in each enterprise. The next step involves a survey in the selected SMEs, which was performed by interview in 10 companies in line with the reference model. Based on the result research in the sales area in SMEs, the set of values of the strategic-knowledge resources of a company is defined according to a reference model SME (see Table 1).

Table 1. The set of values of the strategic-knowledge resources of a company according to a reference model SME

\begin{tabular}{|c|c|c|c|c|c|}
\hline SME/sale area & $\begin{array}{c}m 1 \\
\text { Sales Director }\end{array}$ & $\begin{array}{c}m 2 \\
\text { Sales Specialist }\end{array}$ & $\begin{array}{c}m 3 \\
\text { Marketing Specialist }\end{array}$ & $\begin{array}{c}m 4 \\
\text { Regional assistant }\end{array}$ & $\begin{array}{c}\text { m5 } \\
\text { Product manager }\end{array}$ \\
\hline SME1/1 & W SME1/11 = 25 & W SME1/12 $=4$ & W SME1/13 = 12 & W SME1/14 = 13 & W SME1/15 = 16 \\
\hline SME2/1 & W SME2/11 = 19 & W SME2/12 = 13 & W SME2/13 = 18 & W SME2/14 = 19 & W SME2/15 = 18 \\
\hline SME3/1 & W SME3/11 = 21 & W SME3/12 = 15 & W SME3/13 = 12 & W SME3/14 = 12 & W SME3/15 = 20 \\
\hline SME4/1 & W SME4/11 = 15 & W SME4/12 = 12 & W SME4/13 = 14 & W SME4/14 = 17 & W SME4/15 = 16 \\
\hline SME5/1 & W SME5/11 = 12 & W SME5/12 = 17 & W SME5 $/ 13=13$ & W SME5/14 = 15 & W SME5/15 = 17 \\
\hline SME6/1 & W SME6/11 = 17 & W SME6/12 = 9 & W SME6/13 = 12 & W SME6/14 = 8 & W SME6/15 = 16 \\
\hline SME7/1 & W SME7/11 = 21 & W SME7/12 = 13 & W SME7/13 = 19 & W SME7/14 = 19 & W SME7/15 = 18 \\
\hline SME8/1 & W SME8/11 = 21 & W SME8/12 = 18 & W SME8/13 = 12 & W SME8/14 = 16 & W SME8/15 = 19 \\
\hline SME9/1 & W SME9/11 = 15 & W SME9/12 = 12 & W SME9/13= 14 & W SME9/14 = 17 & W SME9/15 = 16 \\
\hline SME10/1 & W SME10/11 = 23 & W SME10/12 = 19 & W SME10/13 = 13 & W SME10/14 = 15 & W SME10/15 = 23 \\
\hline
\end{tabular}

Source: Patalas-Maliszewska and Werthner, 2010.

In order to present our model of strategic-knowledgeresource management in SMEs, we introduced the definition of strategic-knowledge resources (see Fig. 1). The framework is based on the premise that the focus should be placed on the way individual knowledge is used to build the critical capabilities a company requires in order to succeed-on the core processes and activities that enable it to compete.

The framework starts with the identification and the categorisation of strategic-knowledge resources. Work can be evaluated along two dimensions. The first is the level of comparison and assessment, i.e. the degree to which employees need to collaborate and interact. The second is forecasting - the degree, to which employees need to contribute towards the growth of innovative firms. Using these two factors, we have identified the following model.

Using the defined model is crucial in regards to the competitiveness of a company. Integration of resource and competence management in a company is the basis for its development strategy. In further works, the author's Advisory Computer System for Forecasting the Efficiency of Strategic-Knowledge Resources in Small and Medium Enterprises will be presented.

\section{Conclusions}

The concept of strategic knowledge resources encompasses the employees of enterprises together with their education, experience, professional qualifications, work performance, interpersonal relationships and communication skills. Both resource and competence management can be conceived as complementary elements of the complex strategic-knowledge-resource management formation process.

This paper is aimed at new ideas to help determine knowledge resources in SMEs. SMEs should find special support for increasing and improving their knowledge. Such knowledge can then act as a driving force 
Figure 2. A model of strategic-knowledge-resource management in SMEs

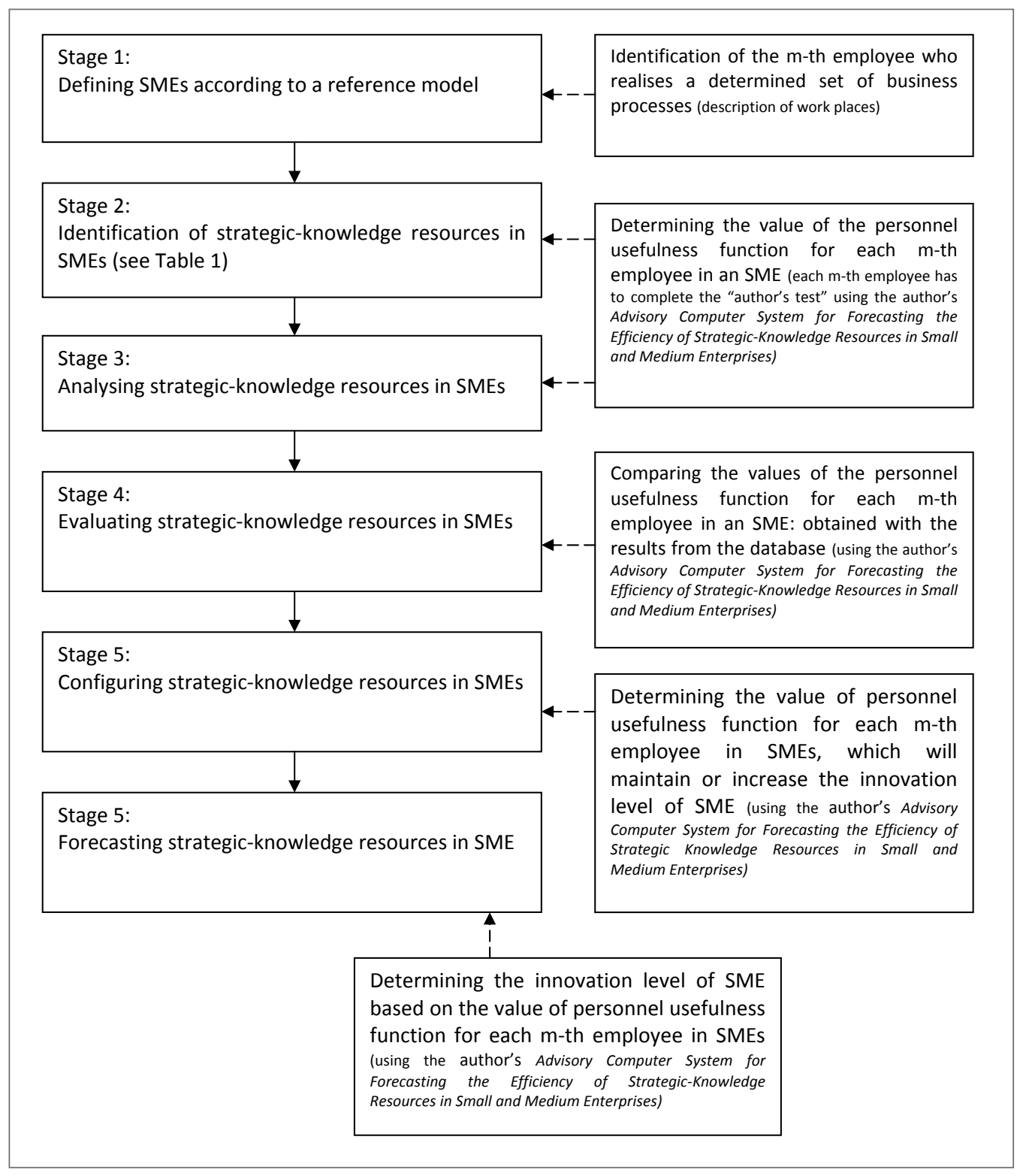

behind the operational stability and the establishment of a permanent competitiveness in the market.

Research is necessary to create economic growth and social development. Creating the author's Advisory Computer System for Forecasting the Efficiency of
Strategic-Knowledge Resources in Small and Medium Enterprises will provide an advantageous tool, which can be used to promote the practice of knowledge management. 


\section{References}

1. Barney, J. (1995). Looking inside for competitive advantage. Academy of Management, Executive, 9(4), 49-61 .

2. Barthelme, F, Ermine, J.L., Rosenthal-Sabroux C. (1998). An architecture for knowledge evolution in organizations. Eur J Oper Res. 109(2), 414-27.

3. Basu, A. (1998). Perspectives on operations research in data and knowledge management. Eur J Oper Res. 111(1), 1-14.

4. Berio, G., Harzallah, M., (2005). Knowledge management for competence management. Journal of Universal Knowledge Management, 0(1), 21-38.

5. Carayannis, EG. (1998). The strategic management of technological learning in project/program management: the role of extranets, intranets and intelligent agents in knowledge generation, diffusion, and leveraging. Technovation, 18(11): 697-703.

6. Chrisman, J.J., Chua, J. H., Zahra, S.A. (2003). Creating wealth in family firms through managing resources: Comments and extensions. Entrepreneurship Theory and Practice, 27(4), 359-365.

7. Davenport, T., Prusak, L. (1998). Working Knowledge: How Organizations Manage What They Know. Harvard Business School Press

8. Draganidis, F., Mentzas G. (2006). Competencybased management: a review of systems and approaches. Inf. Manag. Comput. Security, 14(1), 51-64.

9. Drew, S., (1999). Building knowledge management into strategy. Making sense of a new perspective. Long Range Plann, 32, 130-6.

10. Edvinsson, L., Malone, M. (1997). Intellectual Capital: realizing your company's true value by finding its hidden brainpower. New York, NY: HarperBusiness

11. Hamel, G., Prahalad, C. (1994). Competing for the Future. Boston, Mass.: Harvard Business School Press,

12. Hitt, M. A., Bierman, L., Shimizu, K., Kochhar, R. (2001a). Direct and moderating effects of human capital on strategy and performance in professional service firms: A resource-based perspective. Academy of Management Journal, 44, 13-28.

13. Król, H., Ludwiczyński, A. (2007). Human Resource
Management. Warsaw: PWN

14. Liu, P.L., Yang, S.F., Chen, W.C. (2001). The study of the implementation of knowledge management and its effects on increasing the competition. Chung-Hua Journal of Management, 2(1), 59-74

15. Makadok, R. (2001). Toward a synthesis of the resource-based and dynamic-capability view of rent creation. Strategic Management Journal, 22, 387-401

16. McGrath, R., MacMillan, I. (2000). The Entrepreneurial Mindset. Boston: Harvard Business School Press.

17. Nonaka, L., Takeuchi, H. (1995). The KnowledgeCreating Company. New York: Oxford University Press.

18. Nordhaug, O. (1993). Human Capital in Organizations. Oslo: Scandinavian University Press.

19. Patalas-Maliszewska, J. (2009). The concept of system-supporting decision-making enabling to assets and forecast of knowledge in SMEs - research results. Zilina, Slovak Republic: Applied Computer Science.

20. Patalas-Maliszewska, J., Werthner, H. (2010). The method for assessing and forecasting value of knowledge in SMEs - research results. Contemporary Economics 4(3), 91-106.

21. Purser, RE, Pasmore, WA. (1992). Organizing for learning. Research in organization or change and development. London: JAI Press Inc. 37-114.

22. Sirmon, D.G.,. Hitt, M. A. (2003). Managing resources: linking unique resources, management and wealth creation in family firms. Entrepreneurship Theory and Practice, 27(4), 339-358.

23. Staniewski, M. (2008). Zarzadzanie zasobamiludzkimi a zarządzanie wiedzq $w$ przedsiębiorstwie. Warsaw: WSFiZ.

24. Staniewski, M. (2005). Zarządzanie wiedzą w przedsiębiorstwach - przegląd badań. In: J. Dąbrowski, G. Gierszewska (Eds.), Strategie przedsiębiorstw a zarządzanie wiedzą. Warsaw: WSPiZ.

25. Studer, R, Benjamins, VR, Fensel, D. (1998). Knowledge engineering: principles and methods. Data Knowledge Eng. 25(1-2), 161-97.

26. Zahra, S. A., Hayton, J. C., \& Salvato, C. (2004). Entrepreneurship in family vs. non-family firms: 
A resource-based analysis of the effect of organizational culture. Entrepreneurship Theory \& Practice, 28(4), 363-381.

\section{Acknowledgements}

This work was supported by the Community under a Seventh Framework Programme - People, Marie Curie Intra-European Fellowship for Career Development: "SKnowlnnov (No. 235585)". 